\title{
Is gene expression among women with rheumatoid arthritis dysregulated during a postpartum flare?
}

Matthew Wright ${ }^{1}$, Mette K. Smed ${ }^{2}$, J. Lee Nelson ${ }^{3,4}$, Jørn Olsen ${ }^{5,6}$, Merete L. Hetland ${ }^{7,8}$, Vibeke Zoffmann ${ }^{2,9}$ and Damini Jawaheer ${ }^{1,10^{*}}$ (i)

\begin{abstract}
Background: To evaluate our hypotheses that, when rheumatoid arthritis (RA) flares postpartum, gene expression patterns are altered compared to (a) healthy women, (b) RA women whose disease activity is low or in remission postpartum, and (c) pre-pregnancy expression profiles.

Methods: Twelve women with RA and five healthy women were included in this pilot study. RA disease activity and postpartum flare were assessed using the Clinical Disease Activity Index (CDAl). Total RNA from frozen whole blood was used for RNA sequencing. Differential gene expression within the same women (within-group) over time, i.e., postpartum vs. third trimester (T3) or pre-pregnancy (T0), were examined, using a significance threshold of $q<0.05$ and fold-change $\geq 2$.

Results: Nine of the women with RA experienced a flare postpartum (RAFlare), while three had low disease activity or were in remission $\left(\mathrm{RA}_{\mathrm{NoF}} \mathrm{Flar}\right)$ during that time frame. Numerous immune-related genes were differentially expressed postpartum (vs. T3) during a flare. Fold-changes in expression from T3 to postpartum were mostly comparable between the RA Flare and healthy groups. At 3 months postpartum, compared to healthy women, several genes were significantly differentially expressed only among the RAFlare women, and not among the RA $A_{\text {NoFlare }}$ women. Some of these genes were among those whose "normal" expression was significantly modulated postpartum, and the postpartum expression patterns were significantly altered during the RA flare. There were also some genes that were significantly differentially expressed in RA $A_{\text {Flare }}$ compared to both healthy and RA $A_{\text {NoFlare }}$ women, even though their expression was not significantly modulated postpartum. Furthermore, while postpartum expression profiles were similar to those at pre-pregnancy among healthy women, significant differences were found between those time points among the RAFlare women.

(Continued on next page)
\end{abstract}

\footnotetext{
* Correspondence: Damini.Jawaheer@ucsf.edu

'Children's Hospital Oakland Research Institute, UCSF Benioff Children's

Hospital Oakland, 5700 Martin Luther King Jr. Way, Oakland, CA 94609, USA

${ }^{10}$ University of California San Francisco, San Francisco, CA, USA

Full list of author information is available at the end of the article
}

(C) The Author(s). 2021 Open Access This article is licensed under a Creative Commons Attribution 4.0 International License, which permits use, sharing, adaptation, distribution and reproduction in any medium or format, as long as you give appropriate credit to the original author(s) and the source, provide a link to the Creative Commons licence, and indicate if changes were made. The images or other third party material in this article are included in the article's Creative Commons licence, unless indicated otherwise in a credit line to the material. If material is not included in the article's Creative Commons licence and your intended use is not permitted by statutory regulation or exceeds the permitted use, you will need to obtain permission directly from the copyright holder. To view a copy of this licence, visit http://creativecommons.org/licenses/by/4.0/. The Creative Commons Public Domain Dedication waiver (http://creativecommons.org/publicdomain/zero/1.0/) applies to the data made available in this article, unless otherwise stated in a credit line to the data. 
(Continued from previous page)
Conclusions: The large majority of gene expression changes between T3 and 3 months postpartum among RA
women who flared postpartum reflected normal postpartum changes also seen among healthy women.
Nonetheless, during a postpartum flare, a set of immune-related genes showed dysregulated expression compared
to healthy women and women with RA whose disease activity was low or in remission during the same time
frame, while other genes demonstrated significant differences in expression compared to RA pre-pregnancy levels.

Keywords: Rheumatoid arthritis, Disease activity, Postpartum flare, Gene expression, RNA-seq

\section{Background}

Rheumatoid arthritis (RA) is a chronic systemic inflammatory disease which can lead to progressive joint destruction and disability [1]. The disease, for which there is as yet no cure, affects approximately $1 \%$ of the adult world population, including 1.5 million adults in the USA [2]. Although pregnancy can induce a natural improvement of RA during pregnancy in $50-75 \%$ of women with the disease, this is followed by a predictable flare of the disease in the first 3 to 6 months after childbirth [3].

The biological basis of why the postpartum period predisposes women with RA to a flare has not been the subject of much research. While some studies have reported a decrease in anti-inflammatory cytokines [4], and an increase in T cell activation postpartum [5] in RA, it is not clear if these findings were associated with a flare. Gene expression studies reporting a persistence in monocyte activity and recurrence of lymphocyte gene activity [6], or a molecular activation of monocytes [7] postpartum, included mostly women who were in remission at the postpartum time point. Thus, altogether, the molecular mechanisms that lead to a flare postpartum in RA are still largely unknown. Of interest, systemic biological changes that occur postpartum in healthy women have also not been described.

In the present study, we have examined systemic gene expression changes from the 3rd trimester through to 6 months postpartum in a pilot subset of our prospective cohort of RA and healthy women [8], using RNA sequencing (RNA-seq). We evaluated our hypothesis that postpartum gene expression changes are altered when RA flares, compared to changes that occur among healthy women or women with RA who do not flare, within the same time frame. We examined temporal changes from the 3rd trimester to 3-6 months postpartum within each of these three groups of women to assess how biological changes that occur during a RA flare may overlap with and/or differ from what is observed among healthy women and RA women with low disease activity or in remission. Additionally, we examined whether the gene expression profile by 3 months postpartum reverts to the pre-pregnancy state in healthy women, and whether this is altered in RA.

\section{Subjects and methods Study subjects}

Women with RA and healthy women of Danish descent were enrolled in our ongoing pregnancy study in Denmark, and prospectively followed until at least 6 months after childbirth. A set of 12 women with RA and 5 healthy women from our prospective cohort were included in the present pilot study. Women with RA fulfilled the 1987 revised American College of Rheumatology criteria for RA [9]. Study subjects with other autoimmune conditions were excluded so that those conditions do not confound the associations to be investigated. To enhance the chances of identifying genes that influence RA disease activity, only subjects of Danish ethnicity (parents and grandparents being ethnic Danes) were included. The study was approved by the Ethics Committee for Region Hovedstaden (Protocol \#: H-2-2009-150) and the Data Protection Agency (Data processing ID: RH-2015-02; record \#: i-suite 03601) in Denmark, and by the Children's Hospital Oakland Research Institute Institutional Review Board in the USA (IRB \#: 2009-073). All subjects provided written informed consent prior to enrollment.

\section{RA disease activity and postpartum flare}

Clinical data, including data on disease activity measures, collected before pregnancy (T0), at the third trimester (T3), and at 3 and 6 months postpartum (PP3 and PP6, respectively) were used for analysis. The postpartum time point when disease activity was highest was denoted as PPmax. Women with missing data at T3, PP3, or PP6 were excluded. Because levels of acute phase reactants can fluctuate during and after pregnancy [1012], RA disease activity was assessed at each time point using the Clinical Disease Activity Index (CDAI) [13], which does not include acute phase reactants. Women were classified as having a postpartum flare $\left(\mathrm{RA}_{\text {Flare }}\right)$ if their CDAI state at T3 changed to a worse state by PP3 or PP6. Since this CDAI classification for RA flare is not yet validated, the presence of a flare was also assessed using a validated definition based on the disease activity score based on 28 joints (DAS28) [14]; DAS28 scores with 4 variables including $\mathrm{C}$-reactive protein 
(DAS28CRP4) were computed [15] and an increase in DAS28 of 1.2 units or more between T3 and PPmax, or an increase of at least 0.6 units if the DAS28 at T3 was 3.2 or higher, was used to indicate a flare. Women with RA who did not flare but had low disease activity or were in remission postpartum were denoted as $\mathrm{RA}_{\text {NoFlare }}$.

\section{Sample processing}

Total RNA was extracted from frozen whole blood using the PAXgene Blood RNA kit (Qiagen). RNA integrity assessment, cDNA library preparation, and RNA sequencing (RNA-seq) were performed as previously described [8].

\section{Bioinformatics analyses}

The raw RNA-seq reads were pseudo-aligned to the reference human transcriptome (GRCh38; Ensembl release 98) and quantified using kallisto (version 0.42.4) [16]; transcripts that did not map to a primary chromosome $(1-22, \mathrm{X}, \mathrm{Y})$ or to the mitochondrial transcriptome (MT) were excluded from the reference. Biomart annotations were used to transform transcript-level counts to gene-level counts. Transcripts that mapped to pseudogenes, unannotated genes, and genes with low counts (less than 1 count per million in at least $25 \%$ of samples), as well as any remaining ribosomal RNA (rRNA) and globin transcripts, were filtered out. Any variation in sequencing depth was normalized using the Trimmed Mean of $M$ values (TMM) algorithm as implemented in edgeR (version 3.26.8) [17].

\section{Statistical data analyses}

Study subject characteristics and disease activity scores are presented as mean $\pm \mathrm{SD}$. Differential gene expression analysis was performed with edgeR (version 3.26.8) [18], using genewise generalized linear model (GLM) likelihood ratio tests. A negative binomial distribution was used to account for the over-dispersion in RNA-seq gene counts. To compare pairs of samples from the same women (within-group) at 2 time points, a paired sample design was used. The following within-group comparisons were performed: (1) PPmax vs. T3 (RA Flare only), to identify postpartum gene expression changes when disease activity is maximal; (2) PP3 vs. T3, to identify postpartum expression changes in RA and healthy women; and (3) PP3 vs. T0, to determine whether, by 3 months postpartum, gene expression profiles had reverted to pre-pregnancy status. To identify genes that had significantly different expression levels postpartum in the RA groups compared to healthy women, between-group comparisons $\left(\mathrm{RA}_{\text {Flare }}\right.$ or $\mathrm{RA}_{\mathrm{NoFlare}}$ vs. healthy) were performed at both T3 and PP3. Since samples were sequenced in two batches, sequencing batch was included as a covariate in the GLMs to correct for any batch effects. Medications that the women with RA were taking were not adjusted for. However, to determine whether medications were a potential confounder, sensitivity analyses were performed for the PPmax vs. T3, PP3 vs. T3, and PP3 vs. T0 analyses within the $\mathrm{RA}_{\text {Flare }}$ group, adjusting for medications (yes/no-yes if the woman was currently on corticosteroids or disease-modifying antirheumatic drugs) as a time-varying covariate. A $q$ value threshold of 0.05 was used to assess significance. Because sample sizes were small, fold-changes (FC) in expression were also used in the interpretation of results, focusing on genes differentially expressed by at least 2fold change.

\section{Functional analysis}

WebgestaltR [19] was used to perform enrichment analysis. Gene Ontology (GO) terms and Reactome pathways [20] were analyzed separately, and redundant terms were removed using Webgestalt's "affinity propagation" function. Protein interactions were examined in Cytoscape [21], using data from the STRING database [22].

\section{Results \\ Study subjects}

Nine women with RA ( $\left.\mathrm{RA}_{\text {Flare }}\right)$ and five healthy women had data and samples available at T3, PP3, and PP6. Another 3 women with RA ( $\left.\mathrm{RA}_{\text {NoFlare }}\right)$ had data and samples available at T3 and PP3. Clinical characteristics and medication use among the 12 women with RA are shown in Table 1. RA duration was $($ mean $\pm \mathrm{SD}) 4.8 \pm$ 3.1 years for $\mathrm{RA}_{\text {Flare }}$ and $7.4 \pm 4.4$ years for $\mathrm{RA}_{\mathrm{NoFlare}}$. The average age when they gave birth was $32.7 \pm 4.8$ years for the $\mathrm{RA}_{\text {Flare }}$ women, $30.7 \pm 5.2$ years for the $\mathrm{RA}_{\text {NoFlare }}$ women, and $31.9 \pm 5.7$ years for the healthy women. The average gestational age at birth was $282 \pm 6$ days for $\mathrm{RA}_{\text {Flare, }} 283 \pm 11$ days for $\mathrm{RA}_{\mathrm{NoFlare}}$, and $275 \pm 9$ days for healthy women.

\section{RA disease activity and postpartum flare}

At T3, the $9 \mathrm{RA}_{\text {Flare }}$ women were in remission $(n=4)$ or had low $(n=4)$ or moderate $(n=1)$ disease activity (Fig. 1), with a CDAI score (mean \pm SD) of $4.2 \pm 3.6$. Overall, there was a significant increase in CDAI scores from T3 to PP3 $(14.0 \pm 8.2, p=0.004)$ or when disease activity was maximal (PPmax 16.4 $\pm 7.6, p=0.0005$ ). All 9 women had a flare postpartum, per CDAI classification; CDAI states changed from remission or low disease activity at T3 to moderate disease activity at PPmax for 7 women, and from low or moderate (T3) to high disease activity (PPmax) for 2 women. The CDAI and DAS28 scores were highly correlated $\left(r^{2}=0.88, p<2 \mathrm{E}\right.$ -16). Of the $9 \mathrm{RA}_{\text {Flare }}$ women, 6 satisfied the DAS28 flare criteria. For the $3 \mathrm{RA}_{\mathrm{NoFlare}}$ women, disease activity 
Table 1 Clinical characteristics and medication use among the women with RA

\begin{tabular}{|c|c|c|c|c|c|c|}
\hline \multirow[t]{2}{*}{ Patient } & \multirow{2}{*}{$\begin{array}{l}\text { RA duration* } \\
\text { (years) }\end{array}$} & \multirow[t]{2}{*}{ RF } & \multirow[t]{2}{*}{ ACPA } & \multicolumn{3}{|l|}{ Medication use } \\
\hline & & & & 3rd trimester (T3) & 3 months postpartum (PP3) & 6 months postpartum (PP6) \\
\hline \multicolumn{7}{|l|}{$R A_{\text {Flare }}$} \\
\hline 1 & 10.3 & + & + & PRDL + SSZ & PRDL & PRDL + corticosteroid (Diprospan) \\
\hline 2 & 4.7 & + & + & $\mathrm{PRDL}+\mathrm{SSZ}$ & - & PRDL + MTX \\
\hline 3 & 9.4 & - & + & PRDL + SSZ & PRDL + SSZ & PRDL + glucocorticoid \\
\hline 4 & 2.6 & NA & NA & - & $\mathrm{PRDL}+\mathrm{SSZ}+\mathrm{HCQ}$ & $\mathrm{SSZ}+\mathrm{HCQ}+\mathrm{MTX}$ \\
\hline 5 & 2.1 & NA & + & PRDL & PRDL & PRDL \\
\hline 6 & 3.8 & + & + & SSZ & PRDL + SSZ + MTX & $S S Z+M T X$ \\
\hline 7 & 2.1 & - & - & - & - & PRDL \\
\hline 8 & 5.4 & NA & + & SSZ & PRDL + SSZ & SSZ \\
\hline 9 & 2.4 & - & + & PRDL + SSZ & PRDL + SSZ & PRDL + MTX \\
\hline \multicolumn{7}{|l|}{$R A_{\text {NoFlare }}$} \\
\hline 1 & 9.3 & - & - & - & - & - \\
\hline 2 & 2.4 & + & + & SSZ & MTX & MTX \\
\hline 3 & 10.5 & - & - & Corticosteroid (Diprospan) & - & MTX + IFX \\
\hline
\end{tabular}

RF IgM rheumatoid factor, ACPA anti-citrullinated peptide antibodies, HCQ hydroxychloroquine, MTX methotrexate, PRDL prednisolone, SSZ sulfasalazine, NA not available

*RA duration at delivery

remained low $(n=1)$ or in remission $(n=1)$ or improved from low to remission $(n=1)$ from T3 to PP3, with mean CDAI of $3.4 \pm 0.7$ (T3) and $2.0 \pm 2.7$ (PP3). Only 5 of the 9 women who flared postpartum had data available at pre-pregnancy (T0), and their CDAI score (mean $\pm \mathrm{SD}$ ) at that time point was $6.1 \pm 3.4$.
Postpartum gene expression changes (vs. 3rd trimester) among RA and healthy women

$R A_{\text {Flare }}$ women

Among the $\mathrm{RA}_{\text {Flare }}$ women, 272 genes were significantly differentially expressed $(q<0.05$, fold-change $(\mathrm{FC}) \geq 2)$ between T3 (remission/low disease activity) and PPmax
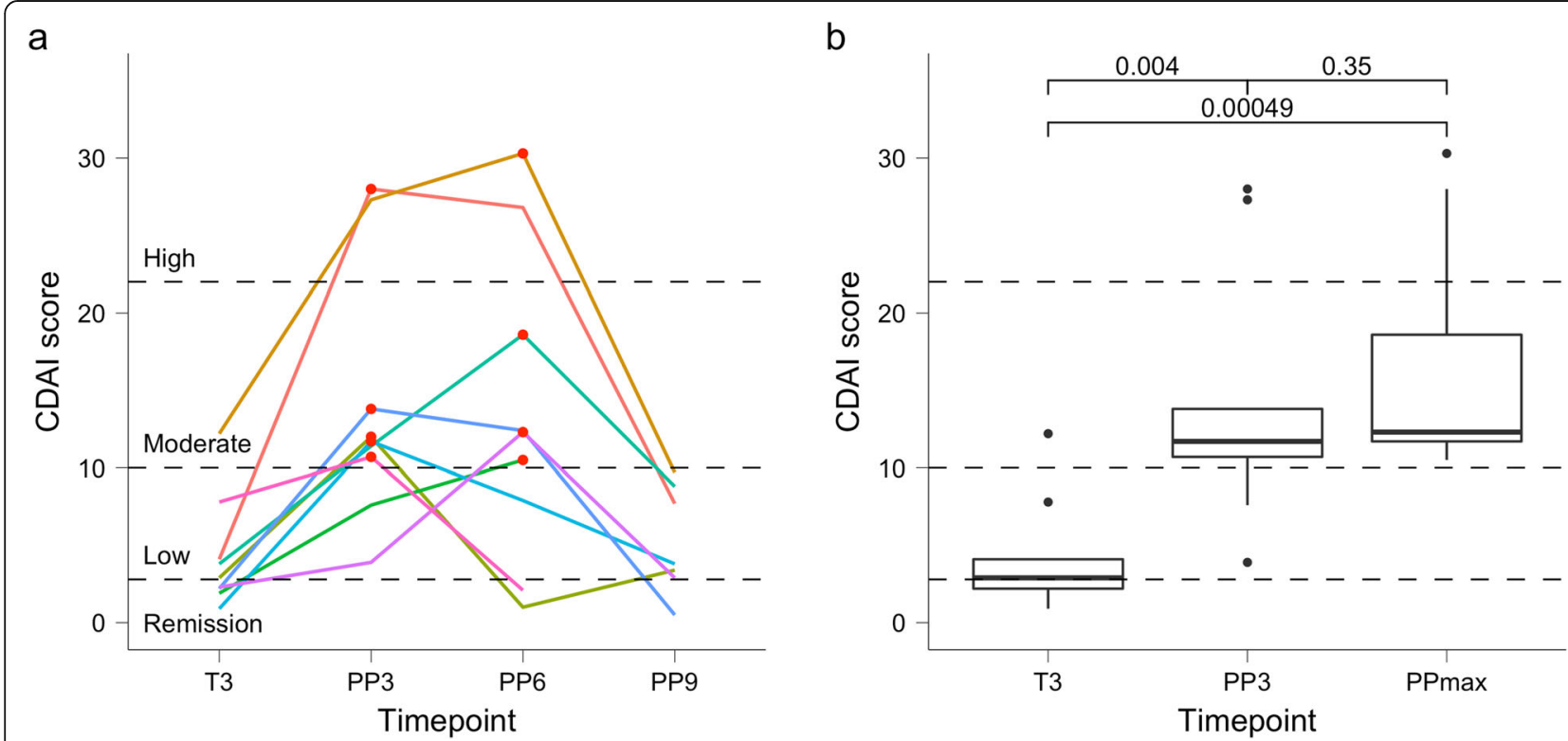

Fig. 1 Changes in disease activity among women who flared postpartum. a Disease activity (CDAl) scores are shown at 3rd trimester (T3) and at 3, 6, and 9 months postpartum (PP3, PP6, and PP9, respectively) for the 9 women with RA who flared postpartum. The maximal postpartum disease activity recorded (PPmax) is marked by a red dot. $\mathbf{b}$ The mean CDAI scores increased significantly from T3 (mean \pm SD, 4.2 \pm 3.6 ) to both PP3 (14.0 $\pm 8.2, p=0.004)$ and PPmax $(16.4 \pm 7.6, p=0.0005)$ 
(maximal disease activity: moderate/high), with most of those genes $(n=261,96 \%)$ being under-expressed at PPmax (Supplementary Table S1). The under-expressed genes included many that were immune-related, such as alpha-defensin genes (DEFA1, DEFA1B, DEFA3, DEFA4), CD177, IFI27, IFIT1B, IL18R1, IL18RAP, IL1B, IL1R1, IL1R2, MMP8, MMP9, S100 genes (S100P, S100A8, S100A9, S100A12), TNFAIP6, MAOA, and CD274 (PD-L1). Genes that were over-expressed at PPmax (vs. T3) included the transcription factor GATA2, HDC, and mitochondrial genes MT-CO2, MT-ND3, and MT-ND6. Additional over-expressed genes that showed more modest fold-changes in expression included IL32, CD27, PTPRCAP, T cell receptor genes, and mitochondrial genes MT-CO1, MT-CO3 $(1.5 \leq \mathrm{FC}<2 ; q<0.05)$. Expression levels of these genes did not change from pre-pregnancy to the 3rd trimester (data not shown). The differentially expressed genes with FC $\geq 2 \quad(n=272)$ were enriched in numerous GO terms related to immune function, including $\mathrm{T}$ helper 1 cell cytokine production $(q=5.6 \mathrm{E}-04)$ and innate immune response in mucosa $(q=7.7 \mathrm{E}-04)$, among others (Table 2). They were also enriched in immune-related Reactome pathways, such as neutrophil degranulation $(q<2.2 \mathrm{E}-16)$ and antimicrobial peptides $(q=1.9 \mathrm{E}-5)$. The protein products of a large proportion of these genes $(n=198$, 73\%) were found to interact with one another.

When comparing the PP3 time point to T3 (instead of PPmax, which encompassed 2 time points: PP3 for 5 women and PP6 for 4 others), significant differential expression $(q<0.05, \mathrm{FC} \geq 2)$ was observed for 204 genes, most of which overlapped with those differentially expressed at PPmax (vs. T3) (Supplementary Table S1). Overall, the fold-changes in expression observed at PPmax and those at PP3 (both compared to T3) were highly correlated (pairwise correlation, 91.6\%) (Fig. 2).

\section{$R A_{\text {NoFlare }}$ women}

Of 51 genes that were significantly differentially expressed at PP3 (vs. T3), the majority ( $n=38$, i.e., $75 \%)$ were over-expressed postpartum, with fold-changes being higher $(2.0 \leq \mathrm{FC} \leq 4.6)$ than those observed among $\mathrm{RA}_{\text {Flare }}$ women; only one of these genes (NKX3-1) was also significantly over-expressed during a flare. There were 13 genes significantly under-expressed at PP3 (vs. T3) in the $\mathrm{RA}_{\text {NoFlare }}$ women, some of which overlapped with those under-expressed among $\mathrm{RA}_{\text {Flare }}$ women (OLFM4, MMP8, CAMP, CRISP3, ABCA13).

Table 2 The genes that were differentially expressed between the third trimester and the time point of maximal disease activity postpartum (PPmax) during the RA flare were enriched in these Gene Ontology (GO) terms

\begin{tabular}{|c|c|c|c|}
\hline GO term & Description & Enrichment ratio & $q$ value \\
\hline GO:0035744 & T helper 1 cell cytokine production & 34.7 & $5.6 \mathrm{E}-04$ \\
\hline GO:0002227 & Innate immune response in mucosa & 19.3 & 7.7E-04 \\
\hline GO:0035456 & Response to interferon-beta & 10.5 & $9.1 \mathrm{E}-03$ \\
\hline GO:0006778 & Porphyrin-containing compound metabolic process & 9.4 & 1.4E-02 \\
\hline GO:0031640 & Killing of cells of other organism & 9.3 & $4.5 \mathrm{E}-04$ \\
\hline GO:0015701 & Bicarbonate transport & 8.3 & $2.2 \mathrm{E}-02$ \\
\hline GO:0019730 & Antimicrobial humoral response & 8.2 & $2.5 \mathrm{E}-06$ \\
\hline GO:0150076 & Neuroinflammatory response & 7.2 & $3.5 \mathrm{E}-02$ \\
\hline GO:0030218 & Erythrocyte differentiation & 7.0 & $1.3 \mathrm{E}-04$ \\
\hline GO:0002444 & Myeloid leukocyte mediated immunity & 7.0 & $<2.2 \mathrm{e}-16$ \\
\hline GO:0051851 & Modification by host of symbiont morphology or physiology & 6.9 & $6.5 \mathrm{E}-03$ \\
\hline GO:0055076 & Transition metal ion homeostasis & 6.2 & $1.4 \mathrm{E}-04$ \\
\hline GO:0097530 & Granulocyte migration & 6.2 & $1.5 \mathrm{E}-04$ \\
\hline GO:0050729 & Positive regulation of inflammatory response & 5.3 & $2.8 \mathrm{E}-03$ \\
\hline GO:1903900 & Regulation of viral life cycle & 5.1 & $3.2 \mathrm{E}-03$ \\
\hline GO:0008645 & Hexose transmembrane transport & 4.6 & $4.3 \mathrm{E}-02$ \\
\hline GO:0071222 & Cellular response to lipopolysaccharide & 4.3 & $3.1 \mathrm{E}-03$ \\
\hline GO:0010950 & Positive regulation of endopeptidase activity & 4.3 & $1.1 \mathrm{E}-02$ \\
\hline GO:0002700 & Regulation of production of molecular mediator of immune response & 4.1 & 4.4E-02 \\
\hline GO:0052548 & Regulation of endopeptidase activity & 3.2 & $2.2 \mathrm{E}-03$ \\
\hline
\end{tabular}

Only the top $20 \mathrm{GO}$ terms (sorted by enrichment ratio) are shown 


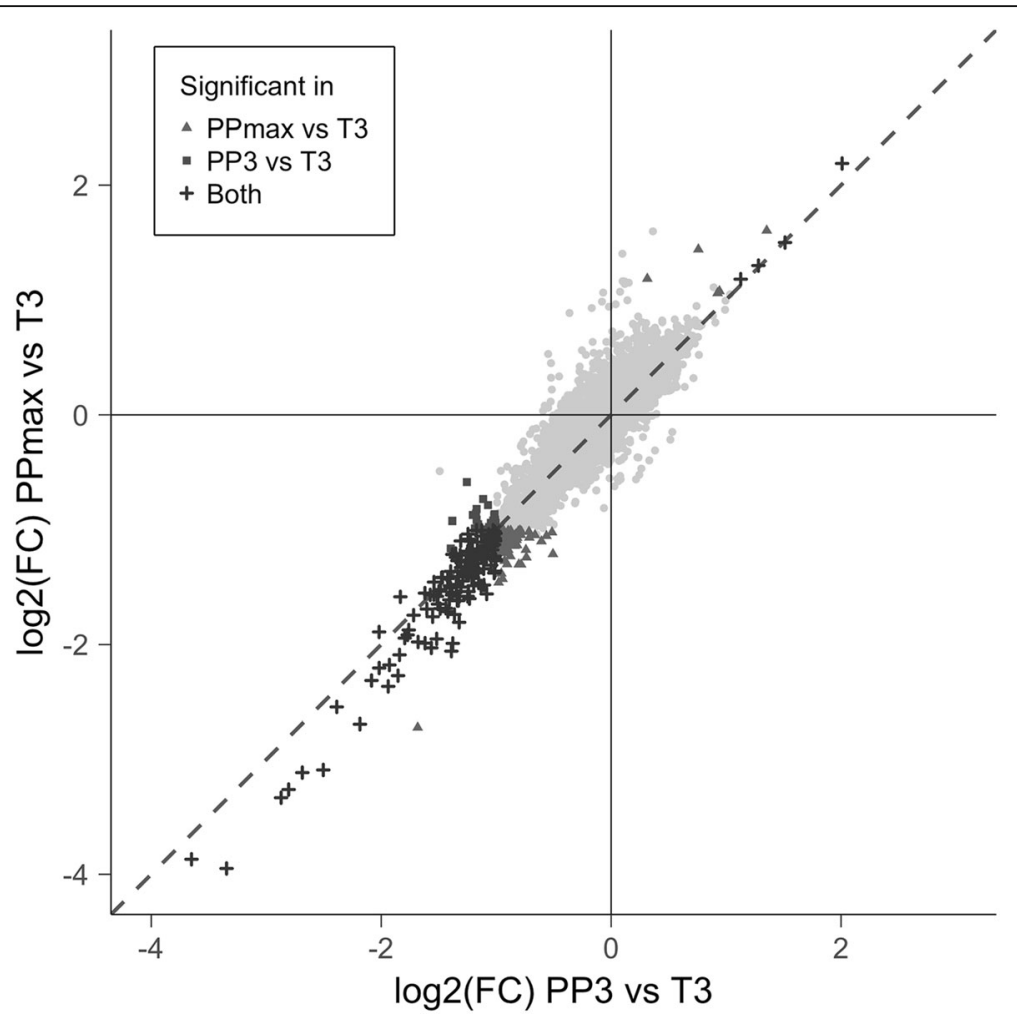

Fig. 2 Postpartum changes in gene expression at PP3 or PPmax among women who flared. The changes in gene expression (log 2 -transformed fold-changes, FC) from the third trimester (T3) to 3 months postpartum (PP3), i.e., PP3 vs. T3 (x-axis), are plotted against those from T3 to the point of maximal disease activity (PPmax), i.e., PPmax vs. T3 (y-axis). All genes are shown, including those that were significantly differentially expressed in one or both comparisons and those that were not significantly differentially expressed in either analysis (gray dots)

\section{Healthy women}

A total of 270 genes showed significant differential expression $(q<0.05, \mathrm{FC} \geq 2)$ between $\mathrm{T} 3$ and PP3, most $(n=254)$ being under-expressed at PP3 (Supplementary Table S2). Among the over-expressed genes $(n=16)$ were GATA2, S1PR5, and HDC. The differentially expressed genes were enriched in various GO terms, including several that were immune-related (Table 3), and in Reactome pathways such as neutrophil degranulation $(q<2.2 \mathrm{E}-16)$ and antimicrobial peptides $(q=1.3 \mathrm{E}-4)$.

\section{Dysregulated postpartum gene expression during the RA flare}

The large majority of genes demonstrated similar expression changes from T3 to PP3, and in the same direction (increase or decrease) in both the RA Flare and healthy groups. For a few genes, however, these temporal changes in expression were smaller in the $\mathrm{RA}_{\text {Flare }}$ than in the healthy group (Fig. 3a; Supplementary Table S2).

Genes were considered to have dysregulated expression during the postpartum flare if their expression at PP3 was significantly different in $\mathrm{RA}_{\text {Flare }}$-but not in the $\mathrm{RA}_{\mathrm{No}}$ Flare - when compared to healthy women. There were a total of 68 such genes, with 50 over-expressed and 18 under-expressed in RA $\mathrm{R}_{\text {Flare }}$ at PP3 (vs. healthy women). Of the 50 genes over-expressed specifically during the flare, a subset $(n=33)$ showed a significant decrease in expression postpartum (from T3 to PP3) among healthy women. These genes showed a smaller decrease in expression among the $\mathrm{RA}_{\text {Flare }}$ women such that by PP3, their levels remained higher than in healthy women (Fig. 3a; Supplementary Table S2). Between-group ( $\mathrm{RA}_{\text {Flare }}$ vs. healthy) differential expression analyses revealed that, when RA flared at PP3, normalized expression levels for these 33 genes were $2-10$-fold higher in $R A(q<0.05)$ than in healthy women (Fig. 3b; Supplementary Table S2). Genes with the largest fold-changes in expression between the $\mathrm{RA}_{\text {Flare }}$ and healthy women $(3.5 \leq \mathrm{FC} \leq 10)$ were OLFM4, DEFA1, DEFA3, DEFA4, MMP8, MAOA, LTF, TUBB2A, ABCA13, CRISP3, CEACAM8, and CAMP. Interestingly, when mean disease activity was low at T3, expression levels of these genes (except MAOA and KRT1) were not significantly different between the $\mathrm{RA}_{\text {Flare }}$ and healthy women (Fig. 3b).

Among the $\mathrm{RA}_{\text {NoFlare }}$ women at PP3, most of the 68 genes with dysregulated expression during a flare were expressed at levels comparable to those in healthy women. Six of them (DEFA3, DEFA4, TUBB2A, 
Table 3 Genes that were differentially expressed between the third trimester (T3) and 3 months postpartum (PP3) among healthy women were enriched in these Gene Ontology (GO) terms

\begin{tabular}{|c|c|c|c|}
\hline GO term & Description & Enrichment ratio & $q$ value \\
\hline GO:0035744 & Thelper 1 cell cytokine production & 25.7 & $1.5 \mathrm{E}-02$ \\
\hline GO:0002227 & Innate immune response in mucosa & 19.0 & $8.2 \mathrm{E}-04$ \\
\hline GO:0033008 & Positive regulation of mast cell activation involved in immune response & 15.8 & $4.9 \mathrm{E}-02$ \\
\hline GO:0006779 & Porphyrin-containing compound biosynthetic process & 11.0 & $3.3 \mathrm{E}-02$ \\
\hline GO:0015701 & Bicarbonate transport & 9.8 & $3.9 \mathrm{E}-03$ \\
\hline GO:0031640 & Killing of cells of other organism & 9.1 & $4.6 \mathrm{E}-04$ \\
\hline GO:0030218 & Erythrocyte differentiation & 8.8 & $2.8 \mathrm{E}-07$ \\
\hline GO:0019730 & Antimicrobial humoral response & 8.7 & $3.1 \mathrm{E}-07$ \\
\hline GO:1990266 & Neutrophil migration & 7.3 & $2.4 \mathrm{E}-05$ \\
\hline GO:0002444 & Myeloid leukocyte mediated immunity & 6.6 & $<2.2 \mathrm{e}-16$ \\
\hline GO:0051851 & Modification by host of symbiont morphology or physiology & 5.9 & $3.9 \mathrm{E}-02$ \\
\hline GO:0050729 & Positive regulation of inflammatory response & 5.7 & $6.6 \mathrm{E}-04$ \\
\hline GO:2000379 & Positive regulation of reactive oxygen species metabolic process & 5.3 & $2.9 \mathrm{E}-02$ \\
\hline GO:0055076 & Transition metal ion homeostasis & 5.1 & 3.7E-03 \\
\hline GO:0032680 & Regulation of tumor necrosis factor production & 4.2 & $4.5 \mathrm{E}-02$ \\
\hline GO:0010951 & Negative regulation of endopeptidase activity & 4.1 & $1.3 \mathrm{E}-03$ \\
\hline GO:0043281 & Regulation of cysteine-type endopeptidase activity involved in apoptotic process & 3.7 & $1.9 \mathrm{E}-02$ \\
\hline GO:0002703 & Regulation of leukocyte mediated immunity & 3.5 & $4.2 \mathrm{E}-02$ \\
\hline GO:0032496 & Response to lipopolysaccharide & 3.2 & 7.7E-03 \\
\hline GO:0034599 & Cellular response to oxidative stress & 3.2 & 2.0E-02 \\
\hline
\end{tabular}

Only the top $20 \mathrm{GO}$ terms (sorted by enrichment ratio) are shown

RNF182, HLA-C, RNASE2) were found to be significantly over-expressed in $\mathrm{RA}_{\text {Flare }}(2 \leq \mathrm{FC} \leq 7.8)$ compared to healthy as well as $\mathrm{RA}_{\text {NoFlare }}$ women (data not shown). Some were over-expressed $(2 \leq \mathrm{FC} \leq 3.6)$ among the $\mathrm{RA}_{\text {NoFlare }}$ women (vs. healthy) at PP3 (Supplementary Table S2), although these differences were not statistically significant. Of the 18 genes that were underexpressed during the RA flare (vs. healthy), 4 genes (IL5RA, SIGLEC8, CLEC4C, NKX3-1) were also significantly under-expressed during the flare compared to the $\mathrm{RA}_{\mathrm{NoFlare}}$ group (data not shown). The 18 genes did not demonstrate any significant longitudinal changes in postpartum expression (T3 to PP3) in either RA or healthy women, except for the NKX3-1 gene which was over-expressed at PP3 (vs. T3) among healthy women.

Functionally, the protein products encoded by several of the 68 genes that appeared to have dysregulated expression in RA during a flare were part of a common interaction network (Fig. 4). The 68 genes were enriched in GO terms such as neutrophil degranulation $(q=4.8 \mathrm{E}-12)$, defense response to bacterium $(q=1.5 \mathrm{E}-8)$, and disruption of cells of other organisms $(q=2.0 \mathrm{E}-5)$, and in Reactome gene sets relating to neutrophil degranulation $(q=8.2 \mathrm{E}-12)$ and antimicrobial peptides $(q=9.1 \mathrm{E}-6)$.

\section{Postpartum vs. pre-pregnancy expression profiles}

Among healthy women, there was no significant differential expression at PP3 $(q>0.05)$, compared to prepregnancy (T0). In contrast, among the $\mathrm{RA}_{\text {Flare }}$ women (using only the women who had data available at T0; $n=$ 5), 231 genes were significantly differentially expressed at PP3 compared to T0 $(q<0.05, \mathrm{FC} \geq 2)$. Of those, 159 were under-expressed at PP3 (e.g., CD177, PADI2, TLR9, NOTCH1, IL4R, IL12B, IL1R1). The 72 over-expressed genes included $7 \mathrm{~T}$ cell receptor alpha and beta variable genes, together with the TRAT1 (T Cell Receptor Associated Transmembrane Adaptor 1) gene, and 20 genes that encoded ribosomal proteins (RPL and RPS genes). Overall, the differentially expressed genes were enriched in the GO terms protein localization to endoplasmic reticulum $(q<2.2 \mathrm{E}-16)$, mRNA catabolic process $(q=$ 9.8E-11), leukocyte degranulation $(q=2.6 \mathrm{E}-3)$, ribosome biogenesis $(q=7.7 \mathrm{E}-3)$, and negative regulation of immunoglobulin mediated immune response $(q=0.02)$ and in the Reactome pathways eukaryotic translation elongation $(q<2.2 \mathrm{E}-16)$ and eukaryotic translation termination $(q<2.2 \mathrm{E}-16)$. Overall, these genes did not show significant differences in postpartum expression between the $\mathrm{RA}_{\text {Flare }}$ and healthy women, except for DLGAP5, NDUFA1, and RPL21. 

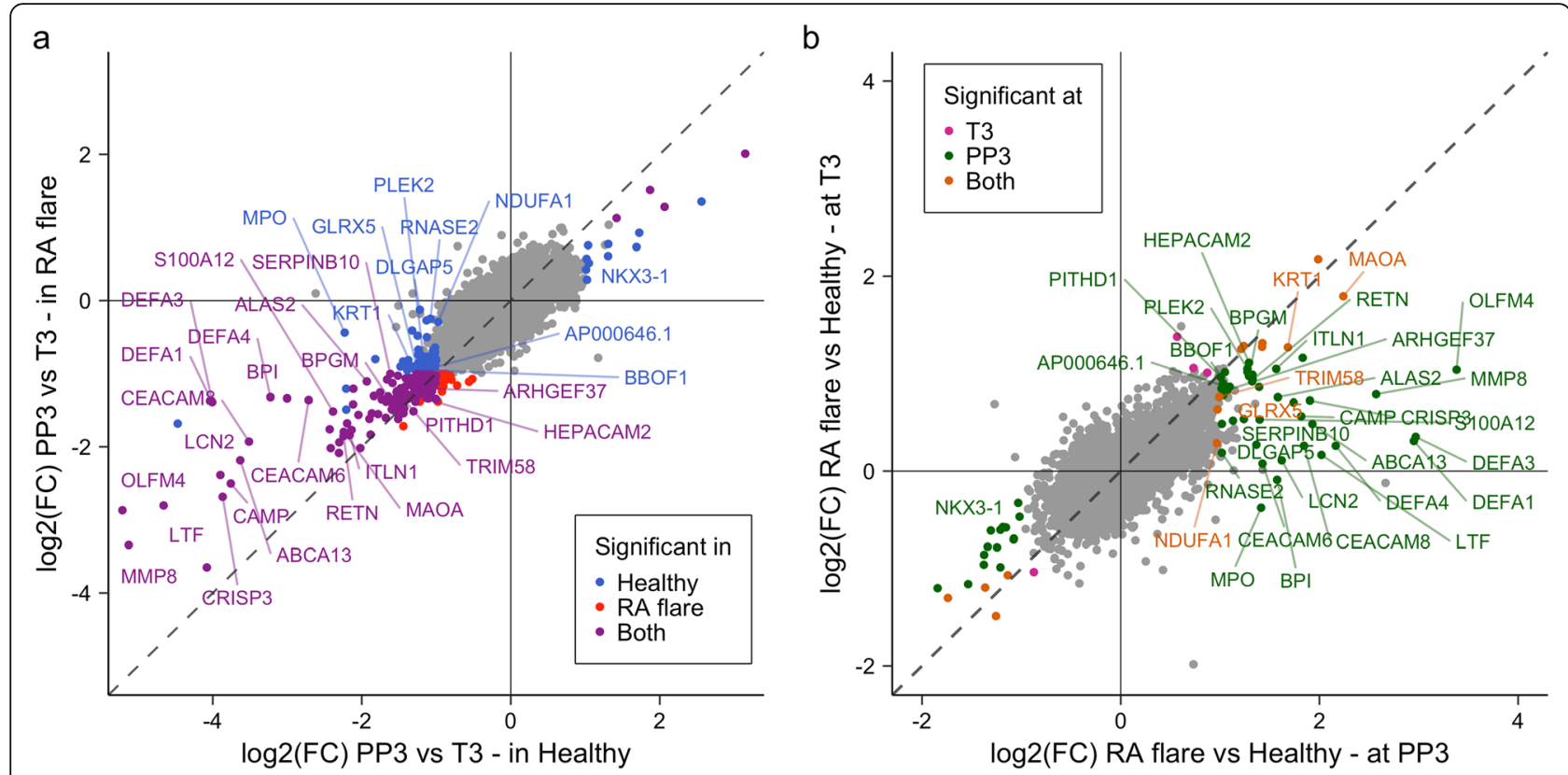

Fig. 3 Some genes whose expression are modulated postpartum in healthy women demonstrate dysregulated expression during the RA postpartum flare. a Log 2 -transformed fold-changes in gene expression from the 3rd trimester (T3) to 3 months postpartum (PP3) are plotted for healthy women ( $x$-axis) and for women with RA who flared postpartum (RA Flare) ( $y$-axis). Several genes $(n=33)$ whose expression levels decreased significantly from T3 to PP3 among healthy women showed a significantly smaller decrease (or increase in the case of NKX3-1) in expression among the women with RA. $\mathbf{b}$ Log $_{2}{ }^{-}$ transformed fold-changes in gene expression for between-group (RA Flare vs. healthy) analyses at PP3 ( $x$-axis) are plotted against those at T3 ( $y$-axis). The 33 genes that had a smaller decrease (or increase) in expression in RA Flare postpartum (PP3 vs. T3 shown in a) did not have significantly different expression levels between the 2 groups of women at T3. At PP3, however, they had significantly (2-10-fold) higher (or lower) expression levels in RA Flare compared to healthy women

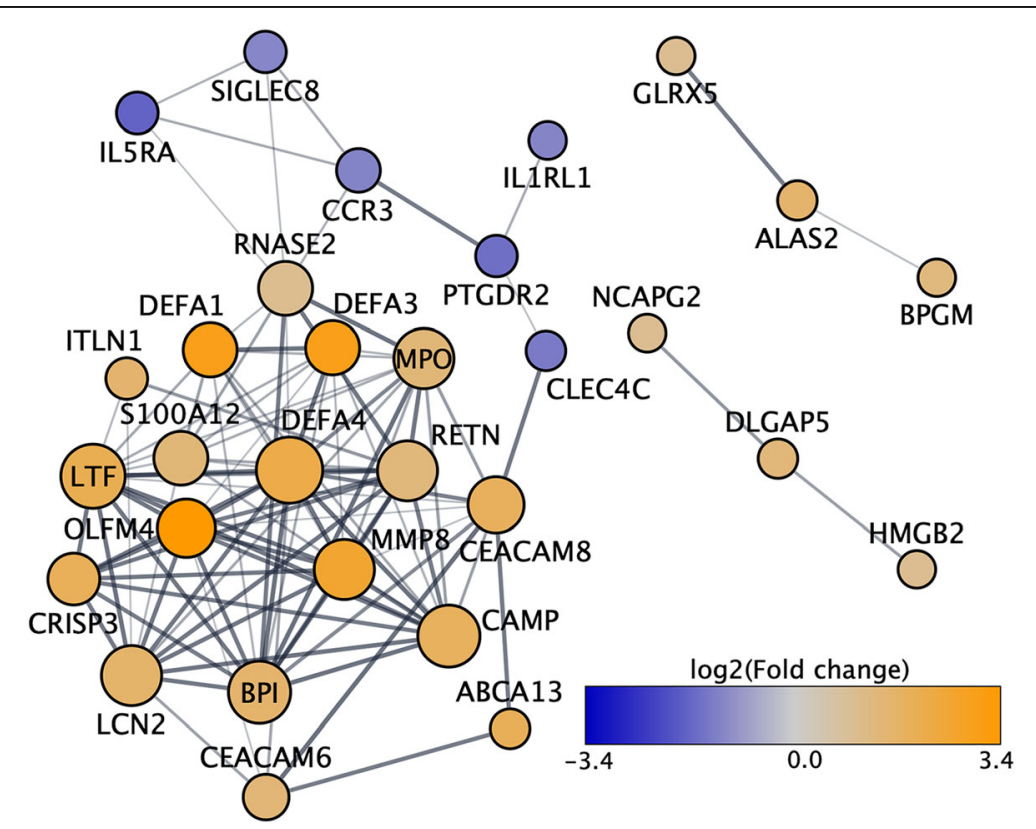

Fig. 4 Interaction network of genes with dysregulated expression during the RA postpartum flare. The proteins encoded by a large proportion of the genes showing dysregulated expression during the RA postpartum flare belonged to a common interaction network 


\section{Sensitivity analysis}

These results presented above for the (i) PPmax vs. T3, (ii) PP3 vs. T3, and (iii) PP3 vs. T0 comparisons within the $\mathrm{RA}_{\text {Flare }}$ group did not change when medications were included as a time-varying covariate in the models; the two sets of results were highly correlated (pairwise correlation $\geq 99.8 \%$ ).

\section{Discussion}

We present here the novel findings from our pilot study which aimed to evaluate two hypotheses. First, we hypothesized that gene expression changes accompanying the predictable postpartum flare in RA are altered compared to changes that occur among healthy women or women with RA whose disease activity is low or in remission within the same time frame. We further hypothesized that, during the RA flare, the postpartum gene expression profile does not revert back to the prepregnancy state.

In our dataset, postpartum changes in gene expression (from T3 to PP3) were mostly similar between $\mathrm{RA}_{\text {Flare }}$ and healthy women, suggesting that many of the changes observed during the RA flare are "normal." However, while expression levels of most genes showing significant changes decreased postpartum in both groups of women, levels did not decrease to the same extent during a RA flare as they did in healthy women. They remained significantly higher in $\mathrm{RA}_{\text {Flare }}$ for numerous genes, including some whose increased expression have previously been associated with RA, such as DEFA1 and DEFA3 [23], LTF [24], MMP8 [25], CAMP [26], CEAC AM8 [27], and CRISP3 [28]. We therefore speculate that postpartum expression of these genes may be dysregulated in RA women who flare, resulting in higher than normal postpartum levels which likely contribute to a pro-inflammatory environment, promoting a flare. This dysregulation appears to happen after childbirth; there were no significant differences in expression levels of these genes (except MAOA and KRT1) between RA and healthy women at the 3rd trimester, when the mean disease activity was low. Additionally, there were some genes that did not show longitudinal changes in expression postpartum, but their expression still appeared to be dysregulated postpartum during a flare, compared to both healthy and $\mathrm{RA}_{\text {NoFlare }}$ women at PP3. Among the genes under-expressed during the RA postpartum flare (vs. healthy or RA $\mathrm{A}_{\mathrm{NoFlare}}$ women at PP3) were the IL5RA and SIGLEC8 genes, both of which play a role in eosinophil apoptosis [29]. The mechanism by which these might trigger a flare is unclear. CLEC4C, which can dampen inflammation [30], was also under-expressed during the RA flare, compared to $\mathrm{RA}_{\mathrm{NoFlare}}$ women. We found some candidate genes that were significantly overexpressed postpartum when RA flared (vs. healthy or
$\mathrm{RA}_{\mathrm{NoFlare}}$ women). Several of those have been implicated in pro-inflammatory processes; for example, HLA-C has been associated with RA [31]; RNF182 was previously reported to be over-expressed in RA [32], and TUBB2A was found to be over-expressed in psoriatic arthritis [33]. Given that the postpartum expression of these genes were dysregulated only during the postpartum flare, and that postpartum expression levels were comparable between healthy and $\mathrm{RA}_{\mathrm{NoFlare}}$ women, we speculate that these genes may play a role in the postpartum flare of RA.

Our results show that, by 3 months postpartum, the gene expression profile among healthy women had reverted back to the pre-pregnancy state. In contrast, among the women with RA, some genes had significantly different expression levels at 3 months postpartum compared to before pregnancy. Contrary to what we expected, though, postpartum expression levels of those genes did not differ significantly between the RA and healthy women, suggesting that their postpartum expression in RA was not dysregulated. Furthermore, among the genes that were under-expressed postpartum (vs. pre-pregnancy) were PADI2 [34, 35], TLR9 [36], and NOTCH1 [37, 38], the increased expression of which have been implicated in RA. It is not clear why these pro-inflammatory genes are expressed at normal levels postpartum in RA, and why they are under-expressed compared to the pre-pregnancy state. We speculate that these genes are most likely not involved in the postpartum flare of the disease. We note that we had previously reported that type I interferon inducible genes may play a role in the pregnancy-induced improvement of RA [39]. Our data presented here suggest that the postpartum flare of RA is not simply a reversal of what happens during the pregnancy-induced improvement of RA, but that these could potentially represent two distinct biological phenomena that may or may not be the driven by the same underlying mechanism.

Although childbirth is often followed by a flare in RA, maternal systemic gene expression changes that accompany this flare had not previously been examined. Only one previous study had examined microarray-based gene expression at 6 months postpartum in RA [6, 7]. However, all but one of the 6 patients in that study were in remission (Rheumatoid Arthritis Disease Activity Index, RADAI $\leq 0.8)$ postpartum [6]. Thus, the gene expression changes reported did not reflect those that accompany a postpartum flare, and are not directly comparable to our findings. Most of the genes differentially expressed in RA were over-expressed at 6 months postpartum (vs. 3rd trimester), and did not overlap with those differentially expressed $(q<0.05, \mathrm{FC} \geq 2)$ in our data at either 3 or 6 months. In that study, postpartum (6 months) profiles of 8 healthy women were also examined, and a large 
proportion of the differentially expressed genes were under-expressed at 6 months postpartum (vs. 3rd trimester), as we also observed in our data; however, other than the DEFA1 and DEFA3 genes, there was little overlap with our findings among healthy women.

It is also not known whether the postpartum flare and a regular (not pregnancy-related) flare in RA share common underlying mechanisms or not. In a recent study of regular flares among 4 patients with RA [40], only few of the genes reported to have expression patterns associated with a flare overlapped with and showed expression changes in the same direction as the ones that we identified during the postpartum flare (HIC1, NRCAM, ALAS2, S100A12). The lack of commonality in the findings between this study and ours, even though Orange et al. used a less stringent significance threshold $(p<0.1)$ than we did, suggests that the mechanism(s) underlying the postpartum flare may indeed differ from those of a regular flare.

Our study has its strengths and limitations. The availability of longitudinal data from the same women enabled us to perform paired analyses, with each woman acting as her own control over time, thus controlling for unmeasured confounders. The use of RNA-seq technology to investigate gene expression was an advantage as it is more accurate and reliable than microarrays. Limitations included the following: First, our sample sizes were small. Nevertheless, the availability of longitudinal data from the same women before, during, and after pregnancy, and the ethnic homogeneity of the study population enhanced the statistical power and, to some extent, enabled us to overcome the limitations of a small sample size. Second, we did not examine changes in proportions of different cell types across time points because our goal was to identify overall systemic gene expression changes, resulting either from altered expression of specific genes or from differences in cell proportions. Third, there is a possibility that specific medications and/or dosage, which were not adjusted for in the analyses, may have confounded the results, although in our sensitivity analysis, we found no such indication.

We plan to use our larger cohort to follow up on these preliminary findings in specific cell types, and to examine epigenetic regulators of expression, including long non-coding RNAs, as potential drivers of the postpartum flare. It will also be important to further examine how the dysregulated gene expression pattern that we observed during the RA postpartum flare compares to those during regular RA flares in a larger set of patients with regular flares.

\section{Conclusions}

Our findings from this pilot study suggest that, although postpartum gene expression patterns in RA were largely similar to those of healthy women, expression of some genes appeared to be dysregulated during a postpartum flare compared to both healthy women and RA women whose disease activity was low or in remission postpartum. We speculate that perhaps these genes could be involved in the postpartum flare of RA. Our results also show that by 3 months postpartum, expression profiles among healthy women reverted back to the prepregnancy state, whereas among RA women who flared postpartum, several genes involved in translation and immune processes among others did not revert to prepregnancy expression levels. These results are nevertheless preliminary and need to be replicated in a larger sample.

\section{Supplementary Information}

The online version contains supplementary material available at https://doi. org/10.1186/s13075-021-02418-w.

Additional file 1: Supplementary Table S1. Genes differentially expressed between 3rd trimester and postpartum among 9 women with RA.

Additional file 2: Supplementary Table S2. Genes differentially expressed between 3rd trimester and 3 months postpartum in RA and/or healthy women.

\section{Abbreviations}

CDAl: Clinical Disease Activity Index; DAS28CRP4: Disease activity scores with 4 variables including C-reactive protein; FC: Fold-change; FDR: False discovery rate; GLM: Generalized linear model; GO: Gene Ontology; HCQ: Hydroxychloroquine; MTX: Methotrexate; PP3: 3 months postpartum; PP6: 6 months postpartum; PPmax: Postpartum time point when disease activity was highest; PRDL: Prednisolone; RA: Rheumatoid arthritis; RADAl: Rheumatoid Arthritis Disease Activity Index; RA flare: Women with RA who flared postpartum; RA $A_{\text {NoFlare: }}$ Women with RA whose disease activity was low or in remission postpartum; RNA-seq: RNA sequencing; rRNA: Ribosomal RNA; SD: Standard deviation; SSZ: Sulfasalazine; T0: Prepregnancy; T3: Third trimester; TMM: Trimmed Mean of $M$ values

\section{Acknowledgements}

We are immensely grateful to the study subjects for their participation in the study. We acknowledge our gratitude towards Dr. Hanne Kjærgaard for all her efforts in setting up the logistics for this study in Denmark; Dr. Kjærgaard passed away in 2013. We also thank the leadership team at the Juliane Marie Center in Denmark for their support. The rheumatology departments at the following hospitals in Denmark facilitated collection of data and samples: Rigshospitalet (Glostrup), Odense Universitetshospital, Dansk Gigthospital (Sønderborg), Aarhus University Hospital (Skejby), and Regionshospitalet Viborg. We thank all members of our project team for making this work possible: Anne-Grethe Rasmussen, Charlotte Schön Frengler, Dorte Heide, Randi Petersen, Tove Thorup Rasmussen, Lone Thomasen, Britta Hvidberg Nielsen, Teresa Rozenfeld, Kirsten Junker, Lis Kastberg Schubert, Lis Lund, Jette Barlach, Helle Bendtsen, Helle Andersen, and Marjo Westerdahl for their contribution with data and sample collection; Rikke Godtkjær Andersen, Mie Rams Rasmussen, Katrine Elmgaard Jensen, Pia Pedersen, Stine Birkelund, Louise Mielke, and Andreas Smed for management of data and samples. We also greatly appreciate valuable assistance provided by DANBIO personnel.

Dr. Damini Jawaheer accepts responsibility for the integrity and validity of the data collected and analyzed.

\section{Authors' contributions}

MW analyzed the data, interpreted the results, and contributed in writing the manuscript. MKS was responsible for acquisition of the data. JLN and JO contributed to the conception and design of the study. MLH and VZ contributed to the data acquisition. DJ was involved in the conception and design of the experiments, in the analysis and interpretation of the data, and in writing the manuscript. All authors contributed to critically revising the 
manuscript for important intellectual content, and gave final approval of the final version of the manuscript.

\section{Funding}

This work was supported by funds from the following: the National Institutes of Arthritis, Musculoskeletal and Skin Diseases (NIAMS), USA (grant R21AR057931); Gigtforeningen, Denmark (grant R87-A1477-B512); and The Juliane Marie Center, Rigshospitalet (Denmark). These funders did not have any role in conducting this study or in interpretation and reporting of results.

\section{Availability of data and materials}

The data and materials are protected by the General Data Protection Regulation (GDPR) of the European Union (2016/679), and by the Danish Data Protection Act enacted in May 2018 to supplement the GDPR. The authors are legally forbidden from sharing data under the terms of their agreement with the Danish Data Protection Agency.

\section{Ethics approval and consent to participate}

This study complies with the Declaration of Helsinki. It was approved by the Ethics Committee for Region Hovedstaden (Denmark), the Danish Data Protection Agency, and the Children's Hospital Oakland Research Institute Institutional Review Board (USA). All subjects provided written informed consent prior to enrollment.

\section{Consent for publication}

Not applicable

\section{Competing interests}

The authors declare that they have no competing interests.

\section{Author details}

'Children's Hospital Oakland Research Institute, UCSF Benioff Children's Hospital Oakland, 5700 Martin Luther King Jr. Way, Oakland, CA 94609, USA. ${ }^{2}$ Juliane Marie Center, Copenhagen University Hospital, Rigshospitalet, Copenhagen, Denmark. ${ }^{3}$ Fred Hutchinson Cancer Research Center, Seattle, WA, USA. ${ }^{4}$ University of Washington, Seattle, WA, USA. ${ }^{5}$ University of California Los Angeles, Los Angeles, CA, USA. ${ }^{6}$ Aarhus University Hospital, Aarhus, Denmark. ${ }^{7}$ DANBIO Registry and Copenhagen Centre for Arthritis Research, Centre for Rheumatology and Spine Diseases VRR, Rigshospitalet, Glostrup, Denmark. ${ }^{8}$ Department of Clinical Medicine, University of Copenhagen, Copenhagen, Denmark. ${ }^{9}$ Department of Public Health, University of Copenhagen, Copenhagen, Denmark. ${ }^{10}$ University of California San Francisco, San Francisco, CA, USA.

\section{Received: 12 August 2020 Accepted: 4 January 2021}

Published online: 18 January 2021

\section{References}

1. Silman AJ, Hochberg MC. Rheumatoid arthritis. In: Epidemiology of the rheumatic diseases. 2nd ed. New York: Oxford University Press; 2001. p. 31-70.

2. Sacks JJ, Luo YH, Helmick CG. Prevalence of specific types of arthritis and other rheumatic conditions in the ambulatory health care system in the United States, 2001-2005. Arthritis Care Res (Hoboken). 2010;62(4):460-4.

3. Nelson JL, Ostensen M. Pregnancy and rheumatoid arthritis. Rheum Dis Clin N Am. 1997;23(1):195-212.

4. Ostensen M, Forger F, Nelson JL, Schuhmacher A, Hebisch G, Villiger PM. Pregnancy in patients with rheumatic disease: anti-inflammatory cytokines increase in pregnancy and decrease post partum. Ann Rheum Dis. 2005; 64(6):839-44.

5. Ostensen M, Sicher P, Forger F, Villiger PM. Activation markers of peripheral blood mononuclear cells in late pregnancy and after delivery: a pilot study. Ann Rheum Dis. 2005:64(2):318-20.

6. Haupl T, Ostensen M, Grutzkau A, Radbruch A, Burmester GR, Villiger PM. Reactivation of rheumatoid arthritis after pregnancy: increased phagocyte and recurring lymphocyte gene activity. Arthritis Rheum. 2008:58(10):2981-92.

7. Haupl T, Ostensen M, Grutzkau A, Burmester GR, Villiger PM. Interaction between rheumatoid arthritis and pregnancy: correlation of molecular data with clinical disease activity measures. Rheumatology (Oxford). 2008; 47(Suppl 3):iii19-22.
8. Mittal A, Pachter L, Nelson JL, Kjaergaard H, Smed MK, Gildengorin VL, Zoffmann V, Hetland ML, Jewell NP, Olsen J, et al. Pregnancy-induced changes in systemic gene expression among healthy women and women with rheumatoid arthritis. Plos One. 2015;10(12):e0145204.

9. Arnett FC, Edworthy SM, Bloch DA, McShane DJ, Fries JF, Cooper NS, Healey LA, Kaplan SR, Liang MH, Luthra HS, et al. The American Rheumatism Association 1987 revised criteria for the classification of rheumatoid arthritis. Arthritis Rheum. 1988;31(3):315-24.

10. Belo L, Santos-Silva A, Rocha S, Caslake M, Cooney J, Pereira-Leite L, Quintanilha A, Rebelo I. Fluctuations in C-reactive protein concentration and neutrophil activation during normal human pregnancy. Eur J Obstet Gynecol Reprod Biol. 2005;123(1):46-51.

11. van den Broe NR, Letsky EA. Pregnancy and the erythrocyte sedimentation rate. BJOG. 2001;108(11):1164-7.

12. Ferguson KK, McElrath TF, Chen YH, Mukherjee B, Meeker JD. Longitudinal profiling of inflammatory cytokines and C-reactive protein during uncomplicated and preterm pregnancy. Am J Reprod Immunol. 2014;72(3): 326-36.

13. Aletaha D, Smolen J. The Simplified Disease Activity Index (SDAI) and the Clinical Disease Activity Index (CDAl): a review of their usefulness and validity in rheumatoid arthritis. Clin Exp Rheumatol. 2005;23(5 Suppl 39): S100-8

14. van der Maas A, Lie E, Christensen R, Choy E, de Man YA, van Riel P, Woodworth T, den Broeder AA. Construct and criterion validity of several proposed DAS28-based rheumatoid arthritis flare criteria: an OMERACT cohort validation study. Ann Rheum Dis. 2013;72(11):1800-5.

15. DAS-score.nl - Home of the DAS. http://www.das-score.nl/. Accessed Dec 2020.

16. Bray NL, Pimentel H, Melsted P, Pachter L. Near-optimal probabilistic RNAseq quantification. Nat Biotechnol. 2016;34(5):525-7.

17. Robinson MD, Oshlack A. A scaling normalization method for differential expression analysis of RNA-seq data. Genome Biol. 2010;11(3):R25.

18. Robinson MD, McCarthy DJ, Smyth GK. edgeR: a Bioconductor package for differential expression analysis of digital gene expression data. Bioinformatics. 2010;26(1):139-40.

19. Liao Y, Wang J, Jaehnig EJ, Shi Z, Zhang B. WebGestalt 2019: gene set analysis toolkit with revamped Uls and APIs. Nucleic Acids Res. 2019;47(W1):W199-205.

20. Jassal B, Matthews L, Viteri G, Gong C, Lorente P, Fabregat A, Sidiropoulos K, Cook J, Gillespie M, Haw R, et al. The reactome pathway knowledgebase. Nucleic Acids Res. 2020:48(D1):D498-503.

21. Shannon P, Markiel A, Ozier O, Baliga NS, Wang JT, Ramage D, Amin N, Schwikowski B, Ideker T. Cytoscape: a software environment for integrated models of biomolecular interaction networks. Genome Res. 2003;13(11): 2498-504.

22. Jensen $\amalg$, Kuhn M, Stark M, Chaffron S, Creevey C, Muller J, Doerks T, Julien $P$, Roth A, Simonovic M, et al. STRING 8--a global view on proteins and their functional interactions in 630 organisms. Nucleic Acids Res. 2009; 37(Database issue):D412-6.

23. Bovin LF, Rieneck K, Workman C, Nielsen H, Sorensen SF, Skjodt H, Florescu A, Brunak S, Bendtzen K. Blood cell gene expression profiling in rheumatoid arthritis. Discriminative genes and effect of rheumatoid factor. Immunol Lett. 2004;93(2-3):217-26.

24. Umekita K, Miyauchi S, Nomura H, Umeki K, Okayama A. Neutrophil-derived lactoferrin induces the inflammatory responses of rheumatoid arthritis synovial fibroblasts via Toll-like receptor 4. Clin Exp Rheumatol. 2019;37(5): 834-41.

25. Tchetverikov I, Ronday HK, Van El B, Kiers GH, Verzijl N, TeKoppele JM, Huizinga TW, DeGroot J, Hanemaaijer R. MMP profile in paired serum and synovial fluid samples of patients with rheumatoid arthritis. Ann Rheum Dis. 2004;63(7):881-3.

26. Teixeira VH, Olaso R, Martin-Magniette ML, Lasbleiz S, Jacq L, Oliveira CR, Hilliquin P, Gut I, Cornelis F, Petit-Teixeira E. Transcriptome analysis describing new immunity and defense genes in peripheral blood mononuclear cells of rheumatoid arthritis patients. PLoS One. 2009;4(8):e6803.

27. Ribon M, Mussard J, Semerano L, Singer BB, Decker P. Extracellular chromatin triggers release of soluble CEACAM8 upon activation of neutrophils. Front Immunol. 2019;10:1346.

28. Chapman EA, Lyon M, Simpson D, Mason D, Beynon RJ, Moots RJ, Wright HL. Caught in a trap? Proteomic analysis of neutrophil extracellular traps in rheumatoid arthritis and systemic lupus erythematosus. Front Immunol. 2019;10:423. 
29. Nutku-Bilir E, Hudson SA, Bochner BS. Interleukin-5 priming of human eosinophils alters siglec-8 mediated apoptosis pathways. Am J Respir Cell Mol Biol. 2008;38(1):121-4.

30. Dzionek A, Sohma Y, Nagafune J, Cella M, Colonna M, Facchetti F, Gunther G, Johnston I, Lanzavecchia A, Nagasaka T, et al. BDCA-2, a novel plasmacytoid dendritic cell-specific type II C-type lectin, mediates antigen capture and is a potent inhibitor of interferon alpha/beta induction. J Exp Med. 2001;194(12):1823-34.

31. Siegel RJ, Bridges SL Jr, Ahmed S. HLA-C: an accomplice in rheumatic diseases. ACR Open Rheumatol. 2019;1(9):571-9.

32. Tan Y, Qi Q, Lu C, Niu X, Bai Y, Jiang C, Wang Y, Zhou Y, Lu A, Xiao C. Cytokine imbalance as a common mechanism in both psoriasis and rheumatoid arthritis. Mediat Inflamm. 2017;2017:2405291.

33. Dolcino M, Ottria A, Barbieri A, Patuzzo G, Tinazzi E, Argentino G, Beri R, Lunardi C, Puccetti A. Gene expression profiling in peripheral blood cells and synovial membranes of patients with psoriatic arthritis. Plos One. 2015; 10(6):e0128262.

34. Sun B, Chang HH, Salinger A, Tomita B, Bawadekar M, Holmes CL, Shelef MA, Weerapana E, Thompson PR, Ho IC. Reciprocal regulation of Th2 and Th17 cells by PAD2-mediated citrullination. JCI Insight. 2019;4(22):e129687. https://doi.org/10.1172/jci.insight.129687.

35. Zhou Y, Chen B, Mittereder N, Chaerkady R, Strain M, An LL, Rahman S, Ma W, Low CP, Chan D, et al. Spontaneous secretion of the citrullination enzyme PAD2 and cell surface exposure of PAD4 by neutrophils. Front Immunol. 2017;8:1200.

36. Lacerte P, Brunet A, Egarnes B, Duchene B, Brown JP, Gosselin J. Overexpression of TLR2 and TLR9 on monocyte subsets of active rheumatoid arthritis patients contributes to enhance responsiveness to TLR agonists. Arthritis Res Ther. 2016;18:10.

37. Ando K, Kanazawa S, Tetsuka T, Ohta S, Jiang X, Tada T, Kobayashi M, Matsui $\mathrm{N}$, Okamoto T. Induction of Notch signaling by tumor necrosis factor in rheumatoid synovial fibroblasts. Oncogene. 2003;22(49):7796-803.

38. Nakazawa M, Ishii H, Aono H, Takai M, Honda T, Aratani S, Fukamizu A, Nakamura H, Yoshino S, Kobata T, et al. Role of Notch-1 intracellular domain in activation of rheumatoid synoviocytes. Arthritis Rheum. 2001; 44(7):1545-54

39. Goin DE, Smed MK, Pachter L, Purdom E, Nelson JL, Kjaergaard H, Olsen J, Hetland ML, Zoffmann V, Ottesen B, et al. Pregnancy-induced gene expression changes in vivo among women with rheumatoid arthritis: a pilot study. Arthritis Res Ther. 2017;19(1):104.

40. Orange DE, Yao V, Sawicka K, Fak J, Frank MO, Parveen S, Blachere NE, Hale C, Zhang F, Raychaudhuri S, et al. RNA identification of PRIME cells predicting rheumatoid arthritis flares. N Engl J Med. 2020;383(3):218-28.

\section{Publisher's Note}

Springer Nature remains neutral with regard to jurisdictional claims in published maps and institutional affiliations.

Ready to submit your research? Choose BMC and benefit from:

- fast, convenient online submission

- thorough peer review by experienced researchers in your field

- rapid publication on acceptance

- support for research data, including large and complex data types

- gold Open Access which fosters wider collaboration and increased citations

- maximum visibility for your research: over $100 \mathrm{M}$ website views per year

At $\mathrm{BMC}$, research is always in progress.

Learn more biomedcentral.com/submissions 